\title{
COMPARATIVE ANALYSIS OF EDUCATIONAL ACHIEVEMENTS OF STUDENTS OF FULL-TIME AND EXTRAMURAL FORMS OF STUDIES, TRAINEES FOR CHILDREN AND ELEMENTARY TEACHERS AT TRAKIA UNIVERSITY, STARA ZAGORA
}

\author{
Donka Zheleva-Terzieva ${ }^{1}$
}

\begin{abstract}
:
Introduction: The survey carried out covered all students from the second course, specialty "Preschool and Primary School Pedagogy" at the Pedagogical Faculty of Trakia University, Stara Zagora, in full-time and extramural forms of studies.

Purpose of the study: A comparative analysis of academic achievements in the subject "Sport animation in educational environment" of students of full-time and extramural forms of studying for kindergarten and elementary teachers at Thracian University, Stara Zagora.

Methods: A comparative characteristic by age of the method "stem-leaf" with the purpose of reconnaissance (research) analysis of the data was performed. The statistical indicators coefficient of variation, asymmetry, excesses were used. A comparative analysis of the academic achievements of 127 students for the degree of competence after completion of the training course "Sports animation in educational environment" was carried out. The structural differences (relative share, absolute sum, integral coefficient of structural divergence, Spearman and Kendal rank correlation coefficients) between the results of the conducted knowledge verification didactic test and the pedagogical monitoring of the degree of mastered skills and demonstrated relationship at the end of the training were analyzed.

Findings and results: The survey outlined the following summaries: as a whole, the structural differences between the two forms of studies in relation to the acquired knowledge are not great, but the students of full-time form of studies give in the vast majority of cases more correct answers; The "fully mastered skill" assessment is most often greater with students of fulltime form of studies compared to extramural form of studies, On skills and relationships that require greater life experience and discipline, the relative share of this assessment is, in more rare cases, greater for the extramural form of studies.
\end{abstract}

UDC Classification: 378, DOI: https://doi.org/10.12955/pss.v1.84

Keywords: sports animation, competence, students of pedagogical specialties, full-time and extramural forms of studies.

\section{Introduction}

In recent decades, modern society has been characterised by high-tech and dynamic development, which has caused a number of problems related to the insufficient physical activity of adolescents. The data, made public to the "National Health Strategy 2020", for the motor habits of Bulgarian children show troublesome tendencies related to the influence of the family and social environmental factors. This requires an active child health promotion policy, including the creation of conditions for practicing sports activities. This XXI century is characterised with changes in all spheres of life and with new higher requirements for the individual, which is why education is regarded as "continuing, continuous and open to all (...) The orientation of education to the free development of man, to his/her creative initiative, autonomy, competitiveness and mobility, require a change of traditional paradigms in an educational plan" (Tsankov, 2013). In this regard, the Council of Europe, through global initiatives on education, sets clear guidelines for the use of new training models, in line with the needs of individuals and schools (Cabezudo et al., 2010). In a fast-changing world, it is necessary that educators receive up-to-date training and/or additional qualifications tailored to existing problems. "It is educators who are the relationship between the fast developing world and the students who are about to enter it" (Neminska, 2018).

To counteract hypodynamics, the authors propose an author's model for the formation of professional and pedagogical competence for sports and animation activities in an educational environment (Zheleva-Terzieva, 2020). Everything above provoked an organization for creating and introducing the elective discipline "Sports animation in educational environment" at the Faculty of Pedagogy at Trakia University. In line with the age characteristics of preschool and primary school children, the objective of the training is to acquire theoretical-methodical and practical-applied knowledge and skills for the use of physical exercises and different types of games, sports and sports disciplines in sports animation programs (Dimitrova, 2010). The expected results are related to the acquisition of knowledge, skills and relations for realization of sports and animation activities for children during extracurricular and out-of-school activities and school holidays activities.

\footnotetext{
${ }^{1}$ Trakia University, Faculty of Education, donkazeleva@gmail.com
} 
Our interest was motivated by the results obtained from the training of students in II course from EQD "Bachelor", specialty "Preschool and Primary School Pedagogy" in full-time and extramural studies. The difference between the two forms of training consists in the credit hours for the lecture forms (30 hours for full-time and 15 hours for extramural studies, of which the hours for practical classes, fulltime/ extramural: 12/6 hours and for seminars: 18/9 hours) and in the duration of the training course (10 weeks 3 hours for full-time and 2 days, respectively 10 and 5 hours for extramural studies).

\section{Methodology}

The training course was carried out with the above groups of students as follows: during the summer semester of the academic year 2017/2018, the subjects surveyed were 64 students from full-term training and during the winter semester of the academic year 2019/2020 - 63 students from extramural studies. The total number of trained students of the specialty PPSP is 127 , all of the II course. The number of students in full-time and extramural studies is almost the same (64/63) or $50.4 \%$ and $49.6 \%$. Following the completion of the training course, this study was conducted to compare the results obtained in the two different forms of training.

To achieve this goal, a comparative analysis was conducted on the following areas:

- Data of the age indicator;

- Results obtained from a final criterion-oriented didactic test to assess the extent of the acquired knowledge;

- The results of pedagogical observation and expert assessment for establishing the degree of mastered skills for planning, organizing and conducting of sports animation activities;

- The results of pedagogical observation and expert assessment for establishing the extent of the relations of the students from the two groups studied during the course of the training.

\section{Analysis of results}

The analysis of the results was performed according to the criteria: age characteristics, didactic test for establishing acquired knowledge, expert assessment of formed skills and manifested attitudes, as integral parts of the professional-pedagogical competence.

Characteristics by age

As expected, students from full-time and extramural studies training are in most cases of equal or close age. The similarities and differences are characterised by the "stem-sheet" statistical method for the purpose of "reconnaissance" (research) analysis of the data. The results of its application in this case are presented below. For students from the full-form training, the result is presented in Figure 1, and for students of extramural studies - in Figure 2.

\begin{tabular}{|c|l|r|}
\hline \multicolumn{2}{|l|}{ Figure 1: "Stem-leaf" presentation of students, full-time training } \\
\hline Stem & Leaf & Frequency \\
\hline 2 & 0000000000000000000000000000000222222222334566667999 & 51 \\
\hline 3 & 123335566688 & 12 \\
\hline 4 & 4 & 1 \\
\hline \multicolumn{2}{|c|}{ Total } & 64 \\
\hline Source: Author
\end{tabular}

There is a relatively large number of units -64 . Most of the students are of the same or close age. The available asymmetry in the distribution is clearly evident.

\begin{tabular}{|c|l|r|}
\hline \multicolumn{2}{|l|}{ Figure 2: "Stem-leaf" presentation of students, extramural studies } \\
\hline Stem & Leaf & Frequency \\
\hline 2 & 2333333333334444444444555555556666666666666677777778889 & 53 \\
\hline 3 & 001133558 & 9 \\
\hline 4 & 0 & 1 \\
\hline \multicolumn{2}{|l|}{} & 63 \\
\hline \multicolumn{2}{|l|}{ Source: Author }
\end{tabular}

Here too, there is a relatively large number of units -63 . Most of the students are of the same or close age, but there are differences compared to the previous case. It also clearly shows the availability but different asymmetry in the distribution. Common for the distributions considered is the right 
asymmetry. This means that the withdrawal of the units is close to the larger values of the attribute (in this case the age).

After the analysis of the data, statistical methods are applied, in the direction of determining the distribution center. The results of the methods applied on the data for individual groups of learners are listed in the table 1.

Table 1: Statistical indicators characterizing the distribution of student groups by students`age

\begin{tabular}{|l|c|c|c|}
\hline \multicolumn{1}{|c|}{ Indicators } & $\begin{array}{c}\text { Full-form } \\
\text { training }\end{array}$ & $\begin{array}{c}\text { Extramural } \\
\text { studies }\end{array}$ & Total \\
\hline Number of units & 64 & 63 & 127 \\
\hline Arithmetic mean, in years & 24.5 & 26.5 & 25.5 \\
\hline Median, in years & 22.0 & 26.0 & 24.0 \\
\hline Mean, in years & 20 & 26 & 20 \\
\hline Standard deviation, in years & 6.22 & 3.72 & 5.21 \\
\hline Coefficient of variation, in \% & 38.7 & 13.8 & 27.2 \\
\hline Asymmetry coefficient & 1.320 & 1.762 & 1.148 \\
\hline Coefficient of excess & 0.651 & 3.305 & 0.987 \\
\hline Range in years & 24 & 18 & 24 \\
\hline Minimum, in years & 20 & 22 & 20 \\
\hline Maximum, in years & 44 & 40 & 44 \\
\hline Source: Author & \multicolumn{3}{|}{} \\
\hline
\end{tabular}

The summarized results for all 127 students from the specialty of PPSP (full-time and extramural studies) are the following: The lowest age is 20 years and the highest is 44 years. The range of values is 24 years. The arithmetic mean age is 25.5 years. Half of the students are aged up to 24 and the other half is above this age (median 24 years old). The most common age is 20 years (rank 20 years.). The standard deviation of the arithmetic mean of the individual trainees is \pm 5.21 years. The coefficient of variation with a value of $27.2 \%$, which means the comparative homogeneity of the group of students concerned as to their age. The distribution of students by age is of moderate right asymmetry (coefficient 1.148) - extension to the large values of the attribute. There is a normal top orientation (excess 0.987). As noted above, students from both forms of study of this specialty have similar but not exactly the same age allocations (see figure 1 and 2) and differences in the summarised statistical characteristics (see table 1).

\section{Didactical test of knowledge}

Used to assess the degree of acquired knowledge is the unstandardized criterion-oriented didactic test containing 18 tasks: I Group - 15 tasks of a structured close-end type (Bizhkov \& Kraevski, 2007) with 4 variants of response, one of which is correct; II and III group include a total of three tasks where the degree of assessment of knowledge is through a three-tier scale: Does not know, Knows to some extent, Knows: 1 referencing task; 1 short answer task and 1 task to complete (Rapp, 1975). Consistently analysed was the structure of the answers to all questions and the structural differences in the comparisons between the trainees of the full-time and extramural studies were checked. After a detailed examination of the structure and structural differences between the two forms of training in answering the questions asked, some summaries have been made (see table 2).

In both forms of learning, the greatest is the relative share of the correct answers. It ranges most often between 65.6 and $90.6 \%$ in tasks with scaled responses and between 56.2 and $68.3 \%$ for group II and group III tasks.

The size of structural differences is most often in the range between 0.3 and 2.7 points. Only four of the differences (on the 1st, 9th, 10th and 18en tasks) exceeded 3 points $(3.6,3.2,3.4$-and 4.1 points respectively). In answering a total of 10 of the I group tasks, the differences were "beneficial" to students who were trained in full-time form (the relative share of the correct answers was higher than in the extramural studies). In the remaining 5 tasks, the differences are in the "beneficial" of students of extramural studies (the relative share of the correct answers is higher than in full-time training). In the group II and group III tasks, the difference between the relative shares of the Knows degree achieved is only in the benefit of students from extramural studies. 


\begin{tabular}{|c|c|c|c|c|c|}
\hline \multirow[b]{2}{*}{ Task number } & \multicolumn{2}{|c|}{ Correct response ratio, $\%$} & \multirow{2}{*}{$\begin{array}{c}\text { Structural } \\
\text { difference, } \\
\text { points }\end{array}$} & \multirow{2}{*}{$\begin{array}{c}\text { Absolute sum } \\
\text { of structural } \\
\text { differences }\end{array}$} & \multirow{2}{*}{$\begin{array}{c}\text { Integral } \\
\text { coefficient of } \\
\text { structural } \\
\text { difference }\end{array}$} \\
\hline & $\begin{array}{c}\text { Full-form } \\
\text { training }\end{array}$ & $\begin{array}{c}\text { Extramural } \\
\text { studies }\end{array}$ & & & \\
\hline 1 & 76.6 & 73.0 & 3.6 & 7.3 & 7.6 \\
\hline 2 & 71.9 & 71.4 & 0.5 & 0.9 & 0.5 \\
\hline 3 & 76.6 & 76.2 & 0.4 & 3.7 & 2.0 \\
\hline 4 & 79.7 & 77.7 & 2.0 & 3.9 & 2.4 \\
\hline 5 & 79.7 & 77.8 & 1.9 & 3.8 & 2.3 \\
\hline 6 & 79.7 & 79.4 & 0.3 & 3.6 & 2.0 \\
\hline 7 & 90.6 & 88.9 & 1.7 & 3.5 & 1.9 \\
\hline 8 & 89.1 & 90.5 & -1.4 & 3.1 & 1.6 \\
\hline 9 & 85.8 & 82.6 & 3.2 & 6.4 & 3.8 \\
\hline 10 & 89.1 & 85.7 & 3.4 & 9.7 & 4.1 \\
\hline 11 & 71.9 & 71.4 & 0.5 & 6.8 & 3.8 \\
\hline 12 & 75.0 & 76.2 & -1.2 & 3.0 & 1.8 \\
\hline 13 & 81.2 & 82.5 & -1.3 & 3.1 & 1.8 \\
\hline 14 & 65.6 & 66.7 & -1.1 & 2.8 & 1.8 \\
\hline 15 & 75.0 & 76.2 & -1.2 & 2.8 & 1.7 \\
\hline 16 & 56.3 & 58.8 & -2.5 & 5.2 & 3.8 \\
\hline 17 & 65.6 & 68.3 & -2.7 & 5.4 & 3.3 \\
\hline 18 & 56.2 & 60.3 & -4.1 & 8.2 & 5.6 \\
\hline
\end{tabular}

Table 3: Sorting (rank) by the size of the relative share of the correct answers to the tasks and the form of student $1 \mathrm{~s}$ training

\begin{tabular}{|c|c|c|c|}
\hline \multirow{2}{*}{ Task number } & \multicolumn{2}{|c|}{ Ranks (descending order) } & \multirow{2}{*}{ Difference $(+,-)$} \\
\cline { 2 - 3 } & Full-form training & Extramural studies & -2 \\
\hline 1 & 10 & 12 & 0 \\
\hline 2 & 13.5 & 13.5 & 0 \\
\hline 3 & 9 & 9 & 0 \\
\hline 4 & 8 & 8 & -0.5 \\
\hline 5 & 6.5 & 7 & 0.5 \\
\hline 6 & 6.5 & 6 & -1 \\
\hline 7 & 1 & 2 & 1.5 \\
\hline 8 & 2.5 & 1 & 0 \\
\hline 9 & 4 & 4 & -0.5 \\
\hline 10 & 2.5 & 3 & 0 \\
\hline 11 & 13.5 & 13.5 & 1 \\
\hline 12 & 11.5 & 10.5 & 0 \\
\hline 13 & 5 & 5 & 0 \\
\hline 14 & 15 & 15 & 1 \\
\hline 15 & 11.5 & 10.5 & \\
\hline
\end{tabular}

The absolute sum of structural differences does not reach 10 points anywhere. The integral coefficient of structural divergence does not reach 8 points anywhere. Most of the larger values are due to differences in the incorrect answers chosen by students. 
Next is the arrangement (ranking) in descending order (from the largest to the smallest value) of the relative share of the correct answer to all 15 questions with close-end scaled answers for the two forms of training (full-time and extramural studies). The ranks and differences between them can be found in the table 3 .

In seven of the questions the ranking of the two forms of training is the same (the difference is 0 ). In three questions, the difference (in absolute value) is 0.5 . In three questions, the difference (in absolute value) is 1 , in one 1.5 and in one 2 .

In order to determine the relationship between the arrangement of replies of the students of full-time training, in comparison with those of the extramural studies, the Spearman and Kendall rank correlation coefficients were calculated. Their respective values are 0.982 and 0.931 . They are significant with a probability of less than 0.01 . Both values determine a very large closeness of the measured relation.

The general conclusion is that the structural differences between the two forms of training are not great, but the students of full-time training give, in the vast majority of cases, more faithful answers to the tasks to assess the degree of their knowledge of the course.

Expert assessment of skills and relationships

Below are the results of a survey of 13 skills and 3 personality traits/relationships developed by students, evaluated by direct observation and expert evaluation (Kozhuharova et al., 2012).

Expert assessment of skills

The ratings for the assessment of skills are by means of a three-tier scale: Is capable, Is capable to a certain degree, Is capable. In table 4 data are presented the results of assessing the degree of mastered skills of the persons surveyed (successively to the numbers in the first column correspond the following skills for the realization of sports animation activity: expressing thoughts in writing; work with ICT; expressing thoughts in oral form; duration management; teamwork; management of material resources; refereeing in different types of games; creating a calendar plan for sports-animation activities during a camping; improvisation; preparation of a competition; variability; conflict resolution; analysis and correction).

Table 4: Students in form of training, relative share of skill level shown IS CAPABLE, structural differences, absolute sum of structural differences and integral coefficient of structural difference between the two forms of training

\begin{tabular}{|c|c|c|c|c|c|}
\hline \multirow{2}{*}{ Skill number } & \multicolumn{2}{|c|}{$\begin{array}{l}\text { Relative share of the degree } \\
\qquad I S C A P A B L E, \%\end{array}$} & \multirow{2}{*}{$\begin{array}{l}\text { Structural } \\
\text { difference, } \\
\text { points }\end{array}$} & \multirow{2}{*}{$\begin{array}{l}\text { Absolute sum } \\
\text { of structural } \\
\text { differences }\end{array}$} & \multirow{2}{*}{$\begin{array}{c}\text { Integral } \\
\text { coefficient of } \\
\text { structural } \\
\text { difference }\end{array}$} \\
\hline & $\begin{array}{l}\text { Full-form } \\
\text { training }\end{array}$ & $\begin{array}{l}\text { Extramural } \\
\text { studies }\end{array}$ & & & \\
\hline 1 & 68.7 & 61.9 & 6.8 & 13.6 & 8.4 \\
\hline 2 & 62.5 & 60.3 & 2.2 & 7.4 & 4.5 \\
\hline 3 & 54.7 & 58.8 & -4.1 & 8.2 & 5.6 \\
\hline 4 & 71.8 & 65.1 & 6.7 & 13.4 & 9.1 \\
\hline 5 & 71.9 & 68.2 & 3.7 & 7.4 & 4.9 \\
\hline 6 & 71.9 & 68.3 & 3.6 & 7,2 & 4.2 \\
\hline 7 & 64.0 & 57.2 & 6.8 & 16,6 & 11.1 \\
\hline 8 & 65.6 & 61.9 & 3.7 & 7,4 & 5.2 \\
\hline 9 & 68.7 & 65.0 & 3.7 & 10,0 & 6.3 \\
\hline 10 & 64.1 & 63.5 & 0.6 & 1,2 & 0.8 \\
\hline 11 & 76.6 & 77.8 & -1.2 & 2,6 & 1.7 \\
\hline 12 & 65.6 & 66.7 & -1.1 & 3,0 & 1.8 \\
\hline 13 & 59.4 & 60.3 & -0.9 & 7,8 & 1.1 \\
\hline
\end{tabular}

Expert assessment of relations (personal qualities)

The evaluations to assess the relationship are through a three-tier scale: Low, Medium, High. 


\begin{tabular}{|c|c|c|c|c|c||}
\hline \multirow{3}{*}{$\begin{array}{l}\text { Table 5: Students in form of training, relative share of the highest degree shown HIGH, structural } \\
\text { differences, absolute sum of structural differences and integral coefficient of structural difference }\end{array}$} \\
\hline \multirow{2}{*}{ Type of treatment } & $\begin{array}{r}\text { HIGH degree relative } \\
\text { share, \% }\end{array}$ & $\begin{array}{c}\text { Structural } \\
\text { difference, } \\
\text { points }\end{array}$ & $\begin{array}{c}\text { Absolute sum } \\
\text { of structural } \\
\text { differences }\end{array}$ & $\begin{array}{c}\text { Integral } \\
\text { coefficient of } \\
\text { structural } \\
\text { difference }\end{array}$ \\
\cline { 2 - 3 } & $\begin{array}{c}\text { Full-form } \\
\text { training }\end{array}$ & $\begin{array}{c}\text { Extramural } \\
\text { studies }\end{array}$ & -2.4 & 6.0 & 3.8 \\
\hline Responsibility & 56.3 & 58.7 & 0.6 & 5.2 & 3.8 \\
\hline Creativity & 60.9 & 60.3 & 0.4 & 1.2 & 0.8 \\
\hline Discipline & 75.0 & 74.6 & \multicolumn{3}{|l}{} \\
\hline Source: Author
\end{tabular}

The following summaries are outlined from the results presented for the degree of proficiency of the students, assessed by pedagogical observation and expert assessment: In general, in the case of students of full-time training, compared to extramural studies, the relative share of the assessment "fully mastered skill" is most often greater.

In skills and relationships that require greater life experience and discipline, the relative share of this assessment, in rare cases, is greater for extramural studies.

\section{Conclusions}

As evidenced by the results presented, the highest value indicators of the integral coefficient of structural divergence distinguished between the two forms of training are "expressing thoughts in writing", "duration management" and "refereeing in different types of games", as considered the reason for this may be the limited technological time and the smaller in volume of the realised practical tasks for the mastery of these types of skills by extramural studies students. After the statistical processing of the results, expressed statistically significant differences have not been found in the components knowledge and manifested relationships, as well as in the majority of the mastered skills of students of extramural studies. The presented results convincingly affirm that the training in the course "Sports animation in educational environment" in the two different forms of training is sufficiently effective in terms of the achieved learning outcomes. In the course of the study it was found that the effective readiness of students of a specialty in the field of "Preschool and Primary School Pedagogy" for the acquiring of professional competence for realization of sports animation activity is practically not influenced by the form and duration of the training course "Sports animation in an educational environment".

\section{Literature}

Bizhkov, G., Kraevski, V. (2007). Methodology and methods of pedagogical research. Sofia: University Publishing House "St. Kliment Ohridski".

Cabezudo, A. et al. (2010). Basic guidelines for global education. Concept and methodology for global education for educators and policy makers. Retrieved from https://rm.coe.int/168070eb84

Dimitrova, Z. (2010). For animation as a specific activity and for the need for qualified training of the personnel. Management and education, VI (1), 318-323.

Kozhuharova, G., Ganchev, G., Delchev, M. (2012). Methodology of pedagogical research for students and teachers. Retrieved from www.edu.uni-sz.bg

National Health Strategy 2020, adopted by the Council of Ministers of 21.09.2013. Retrieved from https://www.mh.government.bg/media/filer_public/2016/09/12/nzs_2020.pdf

Neminska, R. (2018). Continuing qualification of teachers - legal and research objective (Scientific-theoretical summary of teacher trainings). Strategies for policy in science and education, 26 (5), 455-475.

Rapp, G. (1975). Messung und Evaluierung von Lernergebnissen in der Schule. Bad Heilbrunn/Obb., Verlag Klinkhard.

Tsankov, N. (2013). Competence for cognitive modeling. Didactic specification and development. Sofia: Avangard Prima.

Zheleva-Terzieva, D. (2020). Model for formation of professional-pedagogical competence for sports-animation activity. Emagazine "Pedagogical Forum", 1. Retrieved from https://www.dipkusz-forum.net. 